\title{
Computed Tomograpy Venography diagnosis of iliocaval venous obstruction in advanced chronic venous insufficiency
}

\author{
Diagnóstico angiotomográfico da obstrução venosa ilíaco-cava na \\ Insuficiência Venosa Crônica avançada \\ Fabio Henrique Rossi', Carlos Alexandre Rosa Gama', Igor Yoshio Imagawa Fonseca', \\ Keilyanne Jaira Ferreira Barros', Thiago Osawa Rodrigues', Ibraim Masciarelli Francisco Pinto', \\ João Alexandre Natividade', Nilo Mitsuru Izukawa'
}

\begin{abstract}
Objective: Iliocaval obstruction is associated with venous hypertension symptoms and may predispose to deep venous thrombosis (DVT). Ultrasonography may fail to achieve noninvasive diagnosis of these obstructions. The possibility of using Computed Tomography Venography (CTV) for these diagnoses is under investigation. Methods: Patients with CVI graded at CEAP clinical classes 3 to 6 and previous treatment failure underwent evaluation with CTV. Percentage obstruction was rated by two independent examiners. Obstruction prevalence and its associations with risk factors and CEAP classification were analyzed. Results: A total of 112 limbs were prospectively evaluated. Mean patient age was 55.8 years and $75.4 \%$ were women. Obstructions involved the left lower limb in $71.8 \%$ of cases and $35.8 \%$ of patients reported a medical history of deep venous thrombosis. Overall, $57.1 \%$ of imaging studies demonstrated venous obstruction of at least $50 \%$ and $10.7 \%$ showed obstruction of $>80 \%$. The only risk factor that was found to be independently associated with a significantly higher incidence of $>50 \%$ venous obstruction was a medical history of DVT ( $p=0.035)$ (Fisher's exact test). There was a positive relationship between clinical classification (CEAP) and degree of venous obstruction in the limbs studied (Chi-square test for linear trend; $p=0.011$ ). Conclusion: Patients with advanced $C V I$ are often affected by obstructions in the iliocaval venous territory and CTV is able to diagnose the degree of obstruction. There is a positive association between degree of obstruction and both previous history of DVT and severity of symptoms of CVI.
\end{abstract}

Keywords: iliac vein; tomography; pathologic constriction; ultrasonography; Doppler.

\begin{abstract}
Resumo
Objetivo: A obstrução ilíaco-cava é associada a sintomas de hipertensão venosa e é um fator de risco para a trombose venosa profunda (TVP). A ultrassonografia pode falhar em seu diagnóstico. Não existe método de "sreening" bem estabelecido. A capacidade da Angiotomografia em realizar esse diagnóstico vem sendo investigada. Método: Pacientes portadores de IVC avançada e com falha no tratamento clínico foram submetidos à Angiotomografia. As imagens foram classificadas quanto ao grau de obstrução por dois investigadores independentes. Foram avaliados a prevalência e o grau de obstrução, e a sua relação com dados demográficos, fatores de risco e sintomas clínicos (CEAP). Resultados: Foram avaliados 112 membros. A idade média dos pacientes foi de 55,8 anos e 75,4\% eram mulheres. A obstrução acometia o membro inferior esquerdo em 71,8\% e havia história de TVP em 35,8\% destes. Em 57,1\% dos membros, havia obstrução $>50 \%$ e, em 10,7\%, a obstrução era > 80\%. A história de TVP foi o único fator demográfico com associação positiva com o grau de obstrução $(p=0,035)$ (teste Exato de Fisher). Houve associação positiva entre a classificação clínica (CEAP) e o grau de obstrução venosa (Teste Qui-quadrado para tendência linear; $p=0,011$ ). Conclusão: Pacientes portadores de IVC avançada são frequentemente acometidos por obstrução venosa ilíaco-cava e a Angiotomografia é capaz de identificar o grau dessa obstrução. Existe uma relação positiva entre o grau de obstrução e a classificação clínica, e a história de TVP.
\end{abstract}

Palavras-chave: veia ilíaca; tomografia; constrição patológica; ultrassonografia; Doppler. 


\section{INTRODUCTION}

Chronic venous insufficiency (CVI) is the most common cause of vascular symptoms that affect the lower limbs. ${ }^{1}$ The importance of venous obstruction in the iliocaval territory to the etiology of these symptoms has been more clearly explained fairly recently, ${ }^{2-4}$ but the prevalence of these obstructions among symptomatic patients is still not yet wellestablished and appears to be underestimated. ${ }^{2,5}$

Endovascular techniques developed to treat these obstructions have produced good clinical results, opening up new prospects for relief of CVI patients' symptoms. . $^{3,6-8}$

The primary objective of supplementary methods for assessment of CVI is to confirm etiology, in addition to locating sites and characteristics of anatomic abnormalities, thereby enabling better treatment planning. Currently, one of the most important questions to answer is which screening method is best for identifying venous obstruction in the iliocaval territory.

Studies have been conducted recently that demonstrate the possibility of using CTV to diagnose venous obstructions in the iliocaval territory. ${ }^{9-13}$ However, no studies exist that have conclusively demonstrated the method's capacity to correlate degree of obstruction with severity of symptoms.

\section{OBJECTIVES}

To evaluate the prevalence of venous obstruction in the iliocaval territory using CTV of the abdomen and pelvis, in patients with advanced CVI. To analyze the possibility of a correlation between degree of venous obstruction in this territory and severity of clinical manifestations, represented by the parameter CEAP classification.

\section{MATERIALS AND METHODS}

The inclusion criterion was presence of CVI with a CEAP classification of $\mathrm{C} 3$ to C6. Patients who met this criterion were recruited at an endovascular interventions clinic run by the Instituto Dante Pazzanese de Cardiologia (IDPC), in São Paulo, Brazil. The study protocol was approved in advance by the IDPC Research Ethics Committee (CEP: 4101/2012).

Exclusion criteria were as follows: patients less than 18 years old; history of allergy to iodinated contrast; peripheral arterial occlusive disease; chronic renal failure; morbid obesity (BMI >
$40 \mathrm{~kg} / \mathrm{m}^{2}$ ); suspected or confirmed pregnancy; and pelvic or abdominal aneurysms.

After signature of free and informed consent forms, data was collected on demographic variables (age; sex; comorbidities; history of deep venous thrombosis [DVT], body mass index, parity, use of oral contraceptive or hormone therapy) and degree of clinical severity (CEAP C 3 - 6) for each patient. If patients had bilateral disease, then each limb was considered separately in the final statistical analysis.

Patients were examined with CTV using a 64-channel Toshiba Aquilion ${ }^{\circledR} \mathrm{CT}$ scanner. Axial slices were acquired of the proximal lower limbs, the pelvis and the abdomen after administration of $80-120 \mathrm{~mL}(1-1.5 \mathrm{~mL} / \mathrm{Kg})$ of Ultra Vist 370 iodinated contrast at a velocity of $3 \mathrm{~mL} / \mathrm{s}$. The Venous phase was conducted 150 seconds after administration of the contrast. The method employed is similar to that proposed by Marston, ${ }^{9}$ but with a reduced volume of contrast, because the contrast employed had a higher iodine concentration and the scans were conducted with a higher capacity for acquisition and resolution of images.

Images were analyzed using PACS ${ }^{\circledR} 11.0$ or OsirixMD ${ }^{\circledR}$ 3.9.4 software. Analysis of the presence of obstructions in iliac veins and cava and of the arteriovenous relationships was conducted using axial, sagittal and coronal slices and also multiplanar reconstructions (MPR). Oblique reconstructions were also used because the arteriovenous relationship in the iliac territory does not occur in a plane that is orthogonal to the direction of tomographic scanning.

The percentage reduction in caliber of the vessel under analysis was calculated as the ratio between the smallest diameter at the point of greatest obstruction and the diameter of the common iliac vein close above the confluence of the ipsilateral internal and external branches. In cases in which the entire length of the iliac vein was involved, the ratio was calculated using the diameter of the contralateral iliac vein. These measurements were taken for the purposes of assessment of the stenosis site and were not compared with each other.

In the event of obstruction of the vena cava, the proportion of obstruction was calculated by taking the ratio between the smallest diameter at the point of greatest obstruction and the diameter measured close below the renal vein.

Obstructions were classified into three categories: Group I: 0 to $49 \%$; Group II: 50 to $79 \%$, or Group III: $\geq 80 \%$. Therefore, group III contained any cases in which total occlusion of the vessel was observed (100\% obstruction). 
All images were assessed by two independent examiners who were blind to the severity of symptoms. In the event of discrepancies in measurements or in the final classification, a third examiner observed the images and defined the final classification category.

Parametric variables observed that were of a qualitative nature were described using frequency statistics (absolute and relative). Quantitative and ordinal measures were described using the summary statistics mean, median, standard deviation (SD), 25th percentile (Per 25) and 75th percentile (Per 75), and minimum (Min) and maximum values (Max).

We used the Fisher's exact test to identify associations between greater than $50 \%$ obstruction and qualitative demographic variables. Ordinal demographic variables and the CEAP clinical classification data were compared between obstruction categories using the nonparametric Kruskal-Wallis test and the chi-square test for linear trend.

The Kappa statistic (a measure of interobserver agreement) was used to describe the degree of agreement between the two initial examiners with relation to the category of obstruction observed on angiotomography.

The significance level adopted for tests was $5 \%$, i.e. we considered differences to be statistically significant when the descriptive level of tests ( $p$ value) was lower than 0.05 .

Data were analyzed using the program SPSS 18.0.

\section{RESULTS}

A total of 57 patients followed the study protocol between March and November of 2012. Table 1 summarizes their demographic data and risk factors for CVI. The only risk factor that exhibited a positive association with obstruction $>50 \%$ was prior history of DVT $(p=0.015)$.

A total of 112 limbs with symptoms of chronic venous insufficiency were assessed. Thirty limbs (26.8\%) exhibited clinical signs and symptoms compatible with a CEAP classification of $\mathrm{C} 3$; while 32 (28.6\%) were compatible with CEAP C4; 24 (21.4\%) with CEAP C5; and 26 (23.2\%) with CEAP C6 (Figure 1).

Venous obstructions observed in the iliocaval venous territory were classified according to the degree of obstruction and by degree of agreement between independent examiners. Forty-eight $(42.9 \%)$ of the limbs had obstruction of less than $50 \% ; 52$ (46.4\%) had obstruction ranging from 50 to $79 \%$, and $12(10.7 \%)$ limbs exhibited obstruction greater than $80 \%$ (Figure 2). The examiners agreed on the obstruction categories assigned to 88 limbs $(78.6 \%$; KAPPA: $0.78 ; p=0.0032$ )

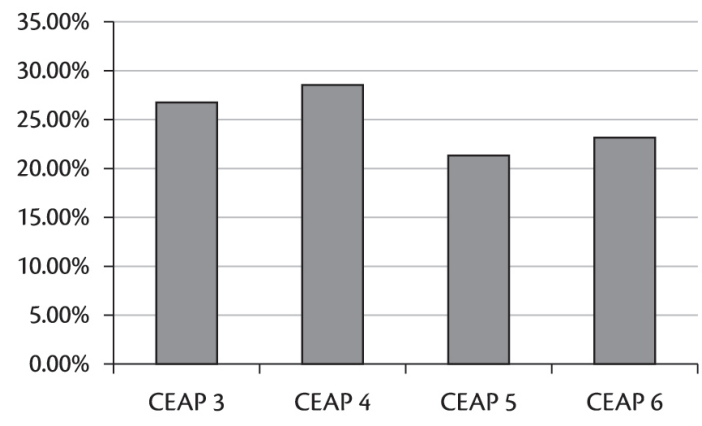

Figure 1. Distribution of severity of clinical symptoms of chronic venous insufficiency by CEAP categories $(n=112)$.

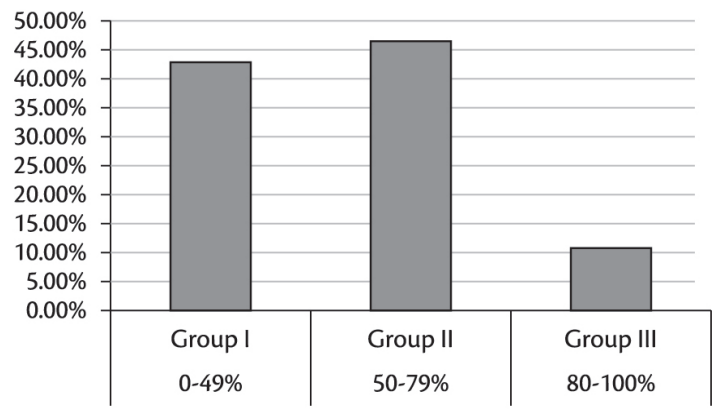

Figure 2. Distribution of degree of obstruction in iliocava venous territory $(n=112)$.

Table 1. Demographic data for patients studied $(n=57)$ and associations with obstructions greater than $50 \%$.

\begin{tabular}{lcccc}
\hline & Obstruction $>50 \%$ & Obstruction $<50 \%$ & Odds ratio & $\mathrm{p}$ \\
\hline${\text { Mean age }{ }^{*}}^{*}$ & 55.4 & 62.4 & 0.82 & 0.26 \\
Female $^{*}$ & $75.4 \%$ & $56.5 \%$ & 1.78 & 0.17 \\
White skin $^{* *}$ & $43 \%$ & $65 \%$ & 0.94 & 0.23 \\
Use of Contraceptives $^{* *}$ & $8.8 \%$ & $12.7 \%$ & 0.78 & 0.14 \\
Hormone replacement $^{* *}$ & $4.5 \%$ & $3.4 \%$ & 1.01 & 0.25 \\
History of deep venous thrombosis $^{*}$ & $35.8 \%$ & $7 \%$ & 8.93 & 0.015 \\
Smoking $^{* *}$ & $15.8 \%$ & $23 \%$ & 0.76 & 0.34 \\
\hline
\end{tabular}

*Kruskal-Wallis test; **Fisher's exact test. 
There was a higher prevalence of obstructions $>$ $50 \%$ in left lower limbs (71.8\%). The initial portion of the left iliac vein (May-Thurner Syndrome) was the most common site of involvement (71.6\%), followed by the left common iliac (15.2\%), the right common iliac (9\%), the left external iliac (3.2\%) and the vena cava $(1.0 \%)$.

A positive association was observed between clinical classification (CEAP) and degree of venous obstruction in the limbs analyzed ( $p=0.011$ according to the chi-square test for linear trend; Table 2).

\section{DISCUSSION}

Compression of the iliac vein, also known as May-Thurner Syndrome or Cockett's Syndrome, is a known anatomic variant. In 1851, Virchow observed that deep venous thrombosis was five times more common in the left lower limb. ${ }^{14}$ The anatomic variant was not described until 1908, when McMurrich did so, believing the phenomenon to be congenital adhesions in the interior of the iliac vein. ${ }^{15}$ In our setting, di Dio, an important Brazilian anatomist, conducted similar work and reported similar results. ${ }^{16}$ However, it was May and Thurner, in $1957,{ }^{17}$ and Cockett, in $1965,{ }^{18}$ who described "spurs" in the interior of the iliac vein, resulting from chronic compression of the vein between the right iliac artery and the spinal column. May and Thurner identified this compression in 22 to $32 \%$ of the cadavers they examined. ${ }^{17}$

Diagnosis of the syndrome is founded on observation of pain, edema or more advanced signs and symptoms of CVI, associated with radiological evidence of vein compression. The diagnostic methods considered the gold standards for identification of these obstructions are phlebography and intravascular ultrasonography, but these are invasive methods and as such are unsuitable for screening or for deciding the best treatment approach for the disease. ${ }^{19}$
Less invasive methods such as transabdominal ultrasonography ${ }^{20}$ and color Doppler ultrasonography ${ }^{21-23}$ may fail to identify both direct and indirect signs of obstruction, because of the deep position of the iliocaval vessels in the pelvis. As a result, angiotomography is under investigation as an important tool for diagnosis of, and screening for, venous obstructions in this territory. ${ }^{9-13,24}$

Kibbe et al. used CTV to determine the prevalence of compression of the left iliac vein in asymptomatic patients. They found that two thirds of the patients they studied had at least $25 \%$ of obstruction and that $24 \%$ exhibited obstruction greater than $50 \%$. They concluded that venous compression may be a common anatomic finding in asymptomatic patients and that this compression can be detected using Angiotomography. ${ }^{10}$

We were unable to identify studies in the literature that determined the incidence of these obstructions in symptomatic patients exclusively using Angiotomography. Wolpert et al. employed Magnetic Resonance Angiography, observing that $37 \%$ of a sample of 24 patients with edema of the left lower limb had venous compression. ${ }^{25}$ Marston et al. determined the incidence of iliocaval obstruction in patients with active or healed ulcers (CEAP 5.6). Sixty-four limbs were studied, 62 using Angiotomography and two using Magnetic Resonance Angiography, and the authors observed that there was at least $50 \%$ obstruction in $37 \%$ of cases and greater than $80 \%$ obstruction in $23 \%$ of the sample. They identified female sex, history of DVT and reflux in the deep vein system as factors that were predictive of obstruction. Marston et al. concluded that venous obstruction is often present in patients with venous hypertension and varicose ulcers. ${ }^{9}$ Oguzkurt et al. conducted a retrospective study in which they found that $68 \%$ of a sample of 34 patients with DVT had greater than $70 \%$ compression. ${ }^{24}$

Our sample was composed exclusively of symptomatic patients with severe CVI (CEAP 3-6)

Table 2. Association between CEAP clinical classification and degree of venous obstruction in patients with advanced CVI $(\mathrm{n}=112)$ (linear association test; $\mathrm{p}=0.011)$.

\begin{tabular}{|c|c|c|c|c|c|c|c|c|c|c|}
\hline & \multicolumn{6}{|c|}{ Degree of Obstruction } & \multicolumn{4}{|c|}{ Total } \\
\hline & \multicolumn{2}{|c|}{ Gl } & \multicolumn{2}{|c|}{ GII } & \multicolumn{2}{|c|}{ GIII } & \multirow[b]{2}{*}{ Count } & \multirow[b]{2}{*}{$\mathrm{N}$} & \multirow[b]{2}{*}{$\%$} & \\
\hline & $\mathrm{N}$ & $\%$ & $\mathrm{~N}$ & $\%$ & $\mathrm{~N}$ & $\%$ & & & & \\
\hline \multirow{4}{*}{ CEAP } & 3 & 18 & $37.5 \%$ & 11 & $21.2 \%$ & 1 & $8.3 \%$ & 30 & $100.0 \%$ & $26.8 \%$ \\
\hline & 4 & 13 & $27.1 \%$ & 15 & $28.8 \%$ & 4 & $33.3 \%$ & 32 & $100.0 \%$ & $28.6 \%$ \\
\hline & 5 & 9 & $18.8 \%$ & 14 & $26.9 \%$ & 1 & $8.3 \%$ & 24 & $100.0 \%$ & $21.4 \%$ \\
\hline & 6 & 8 & $16.7 \%$ & 12 & $23.1 \%$ & 6 & $50.0 \%$ & 26 & $100.0 \%$ & $23.2 \%$ \\
\hline \multicolumn{2}{|c|}{ Total } & 48 & $100.0 \%$ & 52 & $100.0 \%$ & 12 & $100.0 \%$ & 112 & $100.0 \%$ & $100.0 \%$ \\
\hline
\end{tabular}

Chi-square test for linear trend; $p=0.011$. Group I: 0-49\%; Group II: 50-79\%; Group III: $\geq 80 \%$. 
and we found that more than half of the limbs examined (57.1\%) exhibited angiotomographic signs suggestive of greater than $50 \%$ venous obstruction, demonstrating that prevalence is elevated and also showing the importance of the method for diagnosing this condition in symptomatic patients. Our incidence was higher than the rate observed by Martson et al., ${ }^{9}$ since they observed greater than $50 \%$ obstruction in $37 \%$ of the limbs they analyzed. This difference may be the result of certain differences between the two studies. We employed contrast with a higher iodine concentration and tomography with a greater capacity for acquisition and resolution of images, which may have made it possible to identify lesions that would not have been detected using less powerful equipment. In our study, $40(35.8 \%)$ of the limbs analyzed belonged to patients with a prior history of deep venous thrombosis, which could have contributed to the elevated prevalence of obstruction that was observed. Oguzkurt et al. ${ }^{20}$ observed that two thirds of patients with prior history of DVT exhibited $>70 \%$ venous obstruction. Raju et al. also studied patients with severe CVI, using the intravascular ultrasonography method that is currently considered the gold standard, and found that $53 \%$ of the patients studied had greater than $50 \%$ obstruction. ${ }^{4}$

We also observed a positive relationship between severity of symptoms and degree of venous obstruction $(p=0.038)$. These data suggest that venous obstruction in patients with CVI could be an important marker of severity and worse prognosis and confirm results reported in studies published by Raju and Neglen. ${ }^{3,4,7}$

Despite the paucity and lack of hemodynamic studies to determine the degree of obstruction necessary to cause exacerbation of symptoms, by convention, endovascular treatment is prescribed for symptomatic patients with obstructions greater than $50 \% .^{7}$ Implementation of a method that makes it possible to identify the presence of severe obstruction in a less invasive manner than the current gold standard (phlebography and intravascular ultrasonography) could lead to reductions in both the costs and the risks related to screening and treatment of this group of patients.

Another possible advantage of employing CTV is related to the ability it offers to evaluate not only the degree of obstruction, but also its location, extension and mechanism. In common with other studies, we observed that obstruction does not always occur at the point that the right iliac artery and the left iliac vein cross, because it is not always the case that this is the site of the greatest contact. Additionally, it should also be pointed out that other organs and structures can compress parts of the venous system. There was one case in our sample of compression of the vena cava by a retroperitoneal tumor mass, the etiology of which is currently under investigation. ${ }^{4,11,26}$ When cases can be evaluated in advance in this manner, it enables better planning of the tactics and techniques that will be used when treatment is administered.

Our study suffers from certain limitations. First, despite the fact that the angiotomography method employed included control of volume and velocity of contrast infusion, the objective of filling the iliocaval venous territory was not always achieved. This, in turn, limited three-dimensional reconstruction, which would have offered greater accuracy for determination of degree of obstruction, since we are well aware of the tortuosity of the pelvic vessels. We were unaware of the volemic status of the patients who took part in the study, which could have led to overestimation of the degree of obstruction in dehydrated patients. Additionally, the sample of patients described here represent our team's initial experience with assessment of pelvic venous obstructions using angiotomography, which could have been manifest in difficulties with, and failures of, interpretation of the images. This situation may also be demonstrated by the failure of the two observers to agree on obstruction category in $20 \%$ of cases. Another limiting factor in this analysis is that angiotomography is incapable of identifying membranes, spurs and other chronic abnormalities that could be present in CVI patients. We should also bear in mind that the method used here has never been validated by means of comparison with intravascular ultrasonography, currently considered the gold standard, which is evidence of a failure to validate the method recently. Finally, we must point out that a high load of radiation is released during angiotomography and therefore the method should only be employed with patients with advanced CVI and those with relation to whom there is a high degree of suspicion of obstruction on the basis of clinical history and the results of other less invasive methods, such as Doppler ultrasonography.

We conclude that CTV identified a high prevalence of venous obstruction in the iliocaval territory of patients with advanced forms of chronic venous insufficiency. The obstruction is not always located in the initial segment of the left common iliac vein (as in May-Thurner-Cockett syndrome). Severity of symptoms (CEAP) and history of DVT both had positive associations with the degree of obstruction in this territory. 


\section{REFERENCES}

1. Rabe $E$, Partsch $H$, Jünger $M$, et al. Guidelines for clinical studies with compression devices in patients with venous disorders of the lower limb. Eur J Vasc Endovasc Surg. 2008;35(4):494-500. http:// dx.doi.org/10.1016/j.ejvs.2007.08.006. PMid:18249571

2. Raju S. New approaches to the diagnosis and treatment of venous obstruction. J Vasc Surg. 1986;4(1):42-54. http://dx.doi. org/10.1016/0741-5214(86)90321-6. PMid:3522942

3. Neglén P, Thrasher TL, Raju S. Venous outflow obstruction: An underestimated contributor to chronic venous disease. J Vasc Surg. 2003;38(5):879-85. http://dx.doi.org/10.1016/S07415214(03)01020-6. PMid:14603188

4. Raju S, Neglén P. High prevalence of nonthrombotic iliac vein lesions in chronic venous disease: a permissive role in pathogenicity. J Vasc Surg. 2006;44(1):136-43. PMID: 16828437

5. Neglén P, Thrasher TL, Raju S. Venous outflow obstruction: An underestimated contributor to chronic venous disease. J Vasc Surg. 2003;38(5):879-85. http://dx.doi.org/10.1016/S07415214(03)01020-6. PMid:14603188

6. Neglén P, Berry MA, Raju S. Endovascular surgery in the treatment of chronic primary and post-thrombotic iliac vein obstruction. Eur J Vasc Endovasc Surg. 2000;20(6):560-71. http://dx.doi. org/10.1053/ejvs.2000.1251. PMid:11136593

7. Raju S, Darcey R, Neglén P. Unexpected major role for venous stenting in deep reflux disease. J Vasc Surg. 2010;51(2):401-8. http://dx.doi.org/10.1016/j.jvs.2009.08.032. PMid:20006920

8. Delis KT, Bjarnason H, Wennberg PW, Rooke TW, Gloviczki P. Successful iliac vein and inferior vena cava stenting ameliorates venous claudication and improves venous outflow, calf muscle pump function, and clinical status in post-thrombotic syndrome. Ann Surg. 2007;245(1):130-9. http://dx.doi.org/10.1097/01. sla.0000245550.36159.93. PMid:17197976

9. Marston W, Fish D, Unger J, Keagy B. Incidence of and risk factors for iliocaval venous obstruction in patients with active or healed venous leg ulcers. J Vasc Surg. 2011;53(5):1303-8. http://dx.doi. org/10.1016/j.jvs.2010.10.120. PMid:21215568

10. Kibbe MR, Ujiki M, Goodwin AL, Eskandari M, Yao J, Matsumura J. lliac vein compression in an asymptomatic patient population. J Vasc Surg. 2004;39(5):937-43. http://dx.doi.org/10.1016/j. jvs.2003.12.032. PMid:15111841

11. Caggiati A. The left common iliac artery also compresses the left common iliac vein.J Vasc Surg. 2011; 54 (Suppl 6):56S-61S. http:// dx.doi.org/10.1016/j.jvs.2011.06.031

12. Oguzkurt L, Tercan F, Pourbagher MA, Kizilkilic O, Turkoz R, Boyvat F. Computed tomography findings in 10 cases of iliac vein compression (May-Thurner) syndrome. Eur J Radiol. 2005;55(3):421-5. http://dx.doi.org/10.1016/j.ejrad.2004.11.002. PMid:16129251

13. Park E-A, Lee W, Lee MW, et al. Chronic-stage deep vein thrombosis of the lower extremities: indirect CT venographic findings. J Comput Assist Tomogr. 2007;31(4):649-56. http:// dx.doi.org/10.1097/RCT.0b013e31803151d9. PMid:17882048

14. Virchow R. Uber die Erweiterung kleiner Gefasse. Arch Path Anat. 1851;3(3):427-62. http://dx.doi.org/10.1007/BF01960918.

15. McMurrich JP. The occurrence of congenital adhesions in the common iliac veins and their relation to thrombosis of the femoral and iliac veins. Am J Med Sci. 1908;135(3):342-5. http://dx.doi. org/10.1097/00000441-190803000-00004.

16. di Dio L. Estudo anatomico de particularidades normais e patológicas da superfície interna da veia ilíaca comum esquerda: adesões septos e válvulas [Thesis]. Ribeirão Preto: Universidade de São Paulo; 1949.
17. MayR,ThurnerJ. The cause of the predominantly sinistral occurrence of thrombosis of the pelvic veins. Angiology. 1957;8(5):419-27. http://dx.doi.org/10.1177/000331975700800505. PMid:13478912

18. Cockett FB, Thomas ML. The iliac compression syndrome. Br J Surg. 1965;52(10):816-21. http://dx.doi.org/10.1002/ bjs. 1800521028 . PMid:5828716

19. Neglén P, Raju S. Intravascular ultrasound scan evaluation of the obstructed vein. J Vasc Surg. 2002;35(4):694-700. http://dx.doi. org/10.1067/mva.2002.121127. PMid:11932665

20. Oğuzkurt L, Ozkan U, Tercan F, Koç Z. Ultrasonographic diagnosis of iliac vein compression (May-Thurner) syndrome. Diagn Interv Radiol. 2007;13(3):152-5. PMid:17846991.

21. Bach AM, Hann LE. When the common femoral vein is revealed as flattened on spectral Doppler sonography: is it a reliable sign for diagnosis of proximal venous obstruction? AJR Am J Roentgenol. 1997;168(3):733-6. http://dx.doi.org/10.2214/ajr.168.3.9057525. PMid:9057525

22. Lin EP, Bhatt S, Rubens D, Dogra VS. The importance of monophasic Doppler waveforms in the common femoral vein: a retrospective study. J Ultrasound Med. 2007;26(7):885-91. PMid:17592051.

23. de Oliveira A, França GJ, Vidal EA, Stalke PSDB, Baroncini LAV. Duplex scan in patients with clinical suspicion of deep venous thrombosis. Cardiovasc Ultrasound. 2008;6(1):53. http://dx.doi. org/10.1186/1476-7120-6-53. PMid:18937859

24. Oguzkurt L, Ozkan U, Ulusan S, Koc Z, Tercan F. Compression of the left common iliac vein in asymptomatic subjects and patients with left iliofemoral deep vein thrombosis. J Vasc Interv Radiol. 2008;19(3):366-70. http://dx.doi.org/10.1016/j.jvir.2007.09.007

25. Wolpert LM, Rahmani O, Stein B, Gallagher JJ, Drezner $A D$. Magnetic resonance venography in the diagnosis and management of May-Thurner syndrome. Vasc Endovascular Surg. 2002;36(1):51-7. http://dx.doi.org/10.1177/153857440203600109. PMid:12704525

26. Burke RM, Rayan SS, Kasirajan K, Chaikof EL, Milner R. Unusual case of right-sided May-Thurner syndrome and review of its management. Vascular. 2006;14(1):47-50. http://dx.doi. org/10.2310/6670.2006.00012. PMid:16849024

Correspondence
Fabio Henrique Ross
Av Dr. Dante Pazzanese, 500 - Vila Mariana
CEP 04012-909 - São Paulo (SP), Brazi
E-mail: vascular369@hotmail.com

Author information

FHR - PhD in Medicine from the School of Medicine of Universidade de São Paulo (USP). Vascular and endovascular surgeon, Hospital Adventista de São Paulo, and preceptor, Instituto Dante Pazzanese,

São Paulo, SP, Brazil.

CARG, IYIF, KJFB, TOR, JAN - Residents in Vascular and Endovascular Surgery, Instituto Dante Pazzanese, São Paulo, SP, Brazil. IMFP - Cardiologist in charge of the Service of Radiodiagnosis at Instituto Dante Pazzanese, São Paulo, SP, Brazil. NMI - PhD in Medicine from the School of Medicine of USP. Head, Service of Vascular Surgery, Instituto Dante Pazzanese, São Paulo, SP, Brazil.

Author contributions Conception and design: FHR Analysis and interpretation: FHR, CARG, IYIF, KJFB, TOR, JAN Data collection: CARG, IYIF, KJFB, TOR, JAN Writing the article: FHR, CARG, IYIF, KJFB, TOR, JAN Critical revision of the article: FHR, IMFP, NMI. Final approval of the article*: FHR, CARG, IYIF, KJFB, TOR, JAN Statistical analysis: FHR

Overall responsibility: FHR, CARG, IYIF, KJFB, TOR, IMFP, JAN, NMI

${ }^{*}$ All authors have read and approved of the final version of the article submitted to J Vasc Bras. 